\title{
Ciclo celular por Gram y tinción de fluorescencia modificada en bacterias con aspecto morfotintorial semejante a Neisseria gonorrhoeae aisladas de muestras perianales y uretrales
}

\author{
Evelin Margarita Flores Fernández', Luzmila Sofía Albarado Ysasis’.
}

1. Docentes Universidad de Oriente, Núcleo de Sucre, Departamento de Bioanálisis, Venezuela.

Correspondencia: eveflores@cantv.net.

Recibido: 22-01-08 / Aceptado: 05-03-09

\begin{abstract}
Resumen
Se evaluó el ciclo celular por Gram y tinción de fluorescencia modificada en bacterias aisladas de muestras perianales y uretrales, con observación en frotis de diplococcus Gram negativos o diplococcus anaranjados fluorescentes y cultivo negativo para Neisseria gonorrhoeae, de pacientes que acudieron a la consulta ITS-SIDA del ambulatorio "Dr. Arquímedes Fuentes Serrano", Cumaná, Venezuela, con el objetivo de mostrar que en las bacterias aisladas, las características morfotintoriales por Gram y fluorescencia semejantes a diplococos, están asociadas al ciclo celular. Se hizo estudio microscópico del ciclo celular, a partir de cultivos sincrónicos a intervalos de tiempo de 5 minutos por 2 horas, tomando alícuotas, fijando en etanol, realizando extendidos y coloreando con Gram y fluorescencia.

Se identificó Escherichia coli, Enterobacter aerogenes, Klebsiella pneumoniae, Citrobacter koseri, Staphylococcus epidermidis, S. saprophyticus, Streptococcus $\beta$-hemolítico grupo no A-no B y Enterococcus faecalis. Los cocos Gram positivos fueron los que expresaron características morfotintoriales de diplococcus Gram negativos. Streptococcus $\beta$-hemolítico de 0- $15 \mathrm{~min}$, E. faecalis de 60-80 min, S. saprophyticus a los 10 y 35, S. epidermidis a los 0, I 5, 20, 35, 40, 70, 90 y 95 min. Los Staphylococcus por fluorescencia, además de visualizarse como diplococcus anaranjados fluorescentes, se observaron verdes y amarillos. El color varío cíclicamente, iniciando como amarillo, pasando por anaranjado y luego verde. S. saprophyticus de 40- 120 min se obsevaron amarillos fluorescentes. S. epidermidis aún a los 50, 60 y 65 min se visualizaron como diplococcus anaranjados fluorescentes. Se concluye que los cocos Gram positivos presentan fase de diplococcus Gram negativos y anaranjados fluorescentes en su ciclo celular.

Palabras clave: ciclo celular, diplococcus, tinción de Gram, fluorescencia, Staphylococcus.
\end{abstract}

\section{Abstract \\ Cell Cycle by Gram Stain and Modified Fluorescence in Bacteria Resembling Morfotintorial Neisseria Gonorrhoeae Isolated from Anal and Urethral Samples \\ Cell cycle was evaluated by Gram stain and modified fluorescence in bacteria isolated from anal and urethral samples with observation diplococcus smear-negative or fluorescent orange diplococcus and negative culture for Neisseria gonorrhoeae in patients attending Dr. Archimedes Fuentes Serrano's STI-AIDS ambulatory practice}


in Cumana, Venezuela, with the aim of showing that the isolated bacteria, Gram characteristics and fluorescence morfotintoriales like diplococci, are associated with cell cycle. Microscopic study was made of the cell cycle from synchronous cultures at time intervals of 5 minutes for 2 hours, taking aliquots, fixing in ethanol, and extended by coloring with Gram and fluorescence.

Escherichia coli, Enterobacter aerogenes, Klebsiella pneumoniae, Citrobacter koseri, Staphylococcus epidermidis, S. saprophyticus, $\beta$-hemolytic Streptococcus group A no-no B and Enterococcus faecalis were identified. Grampositive cocci were the ones that expressed characteristics of diplococcus morfotintorial negative rods. $\beta$-hemolytic Streptococcus of 0- I 5 min, E. 60-80 min faecalis, S. saprophyticus at 10 and 35, S. epidermidis to 0, I 5, 20, 35, 40, 70, 90 and 95 min. Staphylococcus fluorescence, visualized as diplococcus fluorescent orange, green and yellow were observed. Color varies cyclically, starting as yellow, through orange and then green. S. saprophyticus from 40- 120 min was even observed fluorescent yellow. S. epidermidis even at 50, 60 and 65 min were visualized as fluorescent orange diplococcus. In conclusion, the gram-positive cocci show gram-negative phase and diplococcus fluorescent orange on their cell cycle.

Keywords: cell cycle, diplococci, fluorescence, Gram stain, Staphylococcus

\section{Introducción}

Existe gran analogía entre el ciclo celular bacteriano y el de los organismos eucariotes. Los dos poseen una fase de crecimiento celular y otra en la que se duplica el genoma, que es seguida de la separación de cromosomas, para que finalmente ocurra la división celular $(1,2)$. El ciclo celular bacteriano comprende tres fases: la fase $\mathrm{C}$, caracterizada por la replicación del $\mathrm{ADN}$ cromosómico y es el equivalente a la fase $S$ en eucariotas, una fase $\mathrm{D}$, que comprende el tiempo entre el final de la replicación y la división celular y es conocido como G2 en eucariontes; y la tercera fase, que no tiene un nombre específico, es el período que transcurre desde que nace la célula hija hasta el inicio de la replicación y análoga con la fase G1 en eucariontes. En ambos tipos de ciclos esta fase es la de mayor variabilidad, en la que ocurre la síntesis de ARN y de proteínas, además de otros componentes celulares (3).

En un principio, el conocimiento concerniente a la división celular, se obtuvo empleando modelos experimentales de bacterias Gram positivas y Gram negativas como Escherichia coli, Caulobacter crescentus y Bacillus subtilis; estos modelos han proporcionado información sobre los procesos de replicación y división celular y continúan revelando hallazgos sorprendentes (4). Los avances en técnicas genómicas y de imagen celular han permitido el entendimiento de la fisión en bacterias y organelos; sugiriendo una compleja y gran organización de la célula bacteriana (5-7).

Por el tamaño de la célula bacteriana es complicada la observación por microscopia óptica de los eventos de su ciclo celular. No obstante, es conocido que el estudio cromosómico se realiza por técnicas genéticas y físicas, su observación al microscopio óptico se puede realizar empleando el método histoquímico de Feulgen, también por microscopia de contraste de fase y microscopia de fluorescencia, en esta última, se aplican fluorocromos para ácidos nucleicos como el bromuro de etidio, 4',6'-diamidina-2-fenilindol (DAPI), naranja de acridina, entre otros (8). En la bibliografía se ha encontrado estudios que emplean coloraciones de fluorescencia como métodos complementarios para el estudio del crecimiento celular y material genómico $(5,9,10)$.

De otro lado, en el diagnóstico precoz de la gonorrea y su tratamiento, la evaluación microscópica representa un elemento importante (11). El diagnóstico presuntivo de infección por Neisseria gonorrhoeae en hombres sintomáticos, se realiza a partir de frotis de exudados uretrales coloreados por Gram, al observarse los típicos diplococos Gram negativos dentro de leucocitos polimorfonucleares, representando una herramienta clave para el diagnóstico de 
uretritis gonocóccica en hombres, porque su sensibilidad y especificidad son altas $(12,13)$. La interpretación de frotis coloreados por Gram de muestras endocervicales y rectales se considera difícil, debido a la presencia de bacterias que interfieren con la observación del gonococo o semejan diplococos, como sucede con los cocobacilos Gram negativos Moraxela osloensis, Moraxela phenylpyruvica, Kingella denitrificans y Acinetobacter spp., no recomendándose, por la baja sensibilidad y especificidad $(11,14)$.

Flores y colaboradores reportaron un estudio en frotis de secreciones genitales, que evalúa el método diferencial de fluorescencia con modificación en el pH de la solución de fluoresceína. Con este método se identificó un mayor número de muestras con bacterias que el Gram. Además, observaron que los diplococos emitieron una tinción anaranjada fluorescente, infiriendo asociación a la transcripción de ARN, dentro del ciclo celular (15).

Más tarde, Flores y Albarado, evaluaron la tinción diferencial de fluorescencia modificada en el diagnóstico de gonorrea, obteniendo que la coloración identificó diplococos en muestras perianales y uretrales con diferentes tonalidades (anaranjados y verdes) e intensidades de fluorescencia. La sensibilidad fue alta (100\%) en la identificación de gonococos en frotis. En muestras perianales y uretrales, la especificidad del método de fluorescencia también fue alta $(86 \%$ y $67 \%$, respectivamente), al compararse con el método de Gram (36\% y 50\%, respectivamente), sugiriendo que la baja especificidad por Gram, puede estar dada a la presencia de otros microorganismos con morfología similar a diplococos (16). Este aspecto puede influir en la sensibilidad y especificidad de la coloración de Gram.

La asociación de las variaciones de color por fluorescencia al ciclo celular bacteriano, tuvo como objetivo evaluar el ciclo celular por Gram y tinción de fluorescencia modificada en bacterias aisladas de muestras perianales y uretrales, con observación en frotis de diplococos Gram negativos o diplococos anaranjados fluorescentes y cultivo negativo para $\mathrm{N}$. gonorrhoeae, de pacientes que acudieron a la consulta ITS-SIDA del ambulatorio "Dr. Arquímedes Fuentes Serrano", Cumaná, Venezuela, con la intención de explicar que en las bacterias aisladas las características morfológicas y tintoriales por Gram y fluorescencia semejantes a diplococos están asociadas al ciclo celular.

\section{Materiales y métodos}

\section{Muestra poblacional}

A partir de un muestreo a conveniencia de un total de 37 pacientes del sexo masculino (21 heterosexuales y 16 homosexuales), con sospecha clínica y noción epidemiológica de infección por $N$. gonorrhoeae, se emplearon para el estudio aquellas muestras con observación de diplococos Gram negativos en frotis o diplococos anaranjados fluorescentes por la tinción de fluorescencia modificada y cultivo negativo para $N$. gonorrhoeae. Las muestras empleadas fueron nueve hisopados perianales y tres uretrales transportadas en medio Amies (Difco, USA), que procedieron de pacientes que acudieron a la consulta de Infecciones de Transmisión Sexual (ITS-SIDA) del ambulatorio "Dr. Arquímedes Fuentes Serrano", Cumaná, Venezuela, durante el período comprendido entre julio 2007 y febrero 2008 . Se excluyeron del estudio los pacientes con tratamiento antimicrobiano al momento de la toma de la muestra o antes de las 72 horas.

\section{Aislamiento e identificación de bacterias diferentes a N. gonorrhoeae}

Los hisopos se sembraron en placas que contenían agar sangre (Difco, USA), se incubaron en atmósfera de microaerobiosis a $37^{\circ} \mathrm{C}$ por 24 horas. Posteriormente las placas se inspeccionaron, se evaluaron las características morfológicas de las colonias desarrolladas, así como también, se les practicaron las coloraciones de Gram y fluorescencia, se subcultivaron en agar infusión cerebro corazón (Difco, USA) para purificarlas y realizarles las pruebas de catalasa, oxidasa e identificación bioquímica (17).

\section{Identificación de especies del género Staphylococcus}

Las colonias observadas por Gram como cocos Gram positivos dispuestos en racimos, catalasa positiva y oxidasa negativa, fueron identificadas como miembros del género Staphylococcus. Se sembraron en placas con agar salado manitol (Difco, USA), se incubaron en aerobiosis a $37^{\circ} \mathrm{C}$ por 24 horas. Una vez desarrolladas las colonias se les realizó las pruebas de la coagulasa y novobiocina (17). Identificación de especies de los géneros 


\section{Streptococcus y Enterococcus}

Las colonias pequeñas $\beta$-hemolíticas o no, microscópicamente observadas como cocos Gram positivos dispuestos en cadenas, catalasa y oxidasa negativa, se identificaron como miembros de los géneros Streptococcus o Enterococcus. A estos microorganismos se les realizaron las pruebas de bilis esculina, crecimiento en caldo cloruro de sodio al $6,5 \%$ a una temperatura de $42^{\circ} \mathrm{C}$, que ubica a las bacterias dentro del género Enterococcus. Adicionalmente, a las bacterias $\beta$-hemolíticas se les aplicó la prueba de sensibilidad a la bacitracina y la prueba CAMP para identificar Streptococcus grupo A y B, respectivamente. Las especies del género Enterococcus, se identificaron por medio de las pruebas de fermentación de los hidratos de carbonos (manitol, sorbitol, arabinosa, lactosa y sacarosa), desaminación de la arginina y motilidad. Las pruebas de fermentación se realizaron en medio CTA (Difco, USA) con $1 \%$ del carbohidrato y el indicador rojo de fenol. La desaminación de la arginina se determinó en caldo descarboxilasa de Moeller (Difco, USA) y la motilidad en medio semisólido (17).

\section{Identificación de enterobacterias}

Las colonias desarrolladas en el cultivo primario en agar sangre que presentaron características microscópicas de bacilos Gram negativos, se sembraron en agar MacConkey (Difco, USA) y se incubaron en ambiente de aerobiosis, durante 24 horas. Se evaluó la fermentación de lactosa en el medio y la identificación de especies se realizó empleando pruebas bioquímicas según lineamientos sugeridos por Koneman y colaboradores (17).

\section{Estudio del ciclo celular por microscopia óptica}

Una vez aisladas e identificadas las bacterias de las muestras evaluadas, se les realizó un estudio del ciclo celular, desde un punto de vista de microscopia óptica, con el fin de evidenciar en las bacterias características morfológicas y tintoriales por Gram y fluorescencia semejantes a diplococos dentro de su ciclo celular.

Cultivos en fase exponencial: al inocular una colonia bacteriana en un medio líquido apropiado para su crecimiento no todas las células comienzan a estar fisiológicamente activas. Para lograr que las células de un cultivo alcanzaran la fase de crecimiento óptimo para desarrollar los experimentos, se inocularon $2 \mathrm{~mL}$ de caldo tripticasa de soya (CTS) con una colonia de la cepa con la que se iba a trabajar. El cultivo se incubó a $37^{\circ} \mathrm{C}$ en microaerofilia en el caso de los géneros Enterococcus y Streptococcus, y aerobiosis para el género Staphylococcus y Enterobacterias, durante una noche (18).

Cultivos sincronizados: para obtener información sobre el tipo de crecimiento de las distintas bacterias, debe recurrirse a los cultivos sincrónicos, es decir, a cultivos compuestos por células que se encuentran todas en la misma etapa del ciclo celular. Las mediciones llevadas a cabo en tales cultivos equivalen a las realizadas en las mismas células. Una población sincrónica puede ser seleccionada a partir de una población aleatoria mediante la separación física de células que están en la misma etapa del ciclo celular. Un método excelente de selección para obtener cultivos sincrónicos es la técnica de HelmstetterCummings (HC), basada en el hecho de que algunas bacterias se adhieren fuertemente a las membranas de filtros de nitrato de celulosa (19).

En el presente trabajo se realizó una modificación de la técnica de HC, en vez de filtrar el cultivo bacteriano a través del filtro de nitrocelulosa, se colocaron 5 gotas del cultivo bacteriano en crecimiento exponencial sobre la membrana de filtro de nitrato de celulosa con poros de 0,2 $\mu \mathrm{m}$ y diámetro de $47 \mathrm{~mm}$, ubicada dentro de una placa de Petri estéril, se incubó en las condiciones atmosféricas para cada género por 1 hora o hasta que el líquido fuera absorbido. Inmediatamente se procedió a lavar suavemente con $5 \mathrm{~mL}$ de CTS fresco a $37^{\circ} \mathrm{C}$ empleando pipeta Pasteur, con el fin de separar aquellas células ligadas a la membrana débilmente, las cuales corresponden a las células recién formadas y que se encuentran en la misma etapa del ciclo celular, conservando la sincronía por dos horas aproximadamente. El lavado se recogió en tubos secos estériles y correspondieron a los cultivos sincrónicos que se emplearon para realizar el estudio microscópico del ciclo celular.

Ciclo celular: una vez obtenidos los cultivos sincrónicos, se incubaron inmediatamente en las condiciones correspondientes para cada género bacteriano, tomando alícuotas de $100 \mu \mathrm{L}$ del cultivo en el tiempo 0 y a intervalos de tiempo de 5 minutos por 2 horas y se fijaron en $1,75 \mathrm{~mL}$ de etanol al $74 \%$.

\section{Elaboración de extendidos}


Se procedió a elaborar por duplicado los extendidos a partir de las alícuotas fijadas en etanol, en portaobjetos nuevos, limpios y desengrasados, dejándose secar al aire. Se evaluaron por coloración de Gram y fluorescencia.

\section{Coloración de Gram}

Fue realizada según la técnica de Hucker modificada. La identificación de bacterias en los extendidos se basó en las características morfológicas y tintoriales. Las fotomicrografías fueron tomadas con una cámara y película Kodak Gold 35mm/100 ASA.

\section{Tinción diferencial de fluorescencia modificada}

El extendido preparado se cubrió con naranja de acridina (Sigma-Aldrich, USA) al 0,7\% en buffer acetato $\mathrm{pH}$ 4,0 por 2 minutos, se lavó con agua de chorro y se decoloró con alcohol-acetona (1:1), por 10 segundos, inclinando la lámina en un ángulo de $45^{\circ}$, se enjuagó y aplicó la solución de fluoresceína de sodio (Sigma-Aldrich, USA) a una concentración de $0,002 \%$ en alcohol etílico pH 6,5 por 2 minutos y se eliminó el colorante con agua (7). Se dejó secar para su observación microscópica. Las láminas se observaron con un microscopio de epifluorescencia Olympus BX 60, con filtro de excitación azul de banda amplia de 450-480 nm, espejo dicromático de $500 \mathrm{~nm}$ y un filtro de barrera de $515 \mathrm{~nm}$.

\section{Resultados}

A partir de las muestras perianales y uretrales con observación de diplococos Gram negativos en frotis, Figura 1, y cultivo negativo, se aislaron bacterias Gram negativas y cocos Gram positivos. A nivel perianal Escherichia coli, Enterobacter aerogenes, Klebsiella pneumoniae, Citrobacter koseri, Enterococcus faecalis y Staphylococcus epidermidis. De las muestras uretrales se aisló Streptococcus $\beta$-hemolítico grupo no A-no B, E. faecalis y $S$. saprophyticus, Figura 1.

El estudio microscópico del ciclo celular permitió observar que los cocos Gram positivos fueron los que expresaron características morfotintoriales semejantes a diplococos Gram negativos. Streptococcus $\beta$-hemolítico de 0 a 15 minutos, Figura 2A, E. faecalis a los 60, 70, 75 y 80 minutos, Figura 2B, S. saprophyticus a los 10 y 35, Figura 2C, S. epidermidis a los 0,15, 20, 35, 40, 70, 90 y 95 minutos, Figura 2D. Las especies del género Staphylococcus, por fluorescencia, además de visualizarse como plococos anaranjados fluorescentes, se observaron verdes y amarillos. El color varío nera cíclica, cada 5 minutos, iniciando como amarillo (0, 5 y 20 minutos), pasando or anaranjado (10 y 25 minutos) y verde (15 y 30 minutos) S. saprophyticus a partir de 40 hasta los 120 minutos se observaron amarillos fluorescentes, Figura 2E. S. epidermidis aún a los 50, 60 y 65 minutos se visualizaron como diplococos anaranjados fluorescentes y a partir de los 75 hasta los 120 minutos se observaron amarillos fluorescentes, Figura 2F.

\section{Discusión}

El estudio microscópico por Gram y fluorescencia modificada del ciclo celular en bacterias que procedieron de muestras con observación de diplococos Gram negativos en frotis y cultivo negativo para $N$. gonorrhoeae, confirma
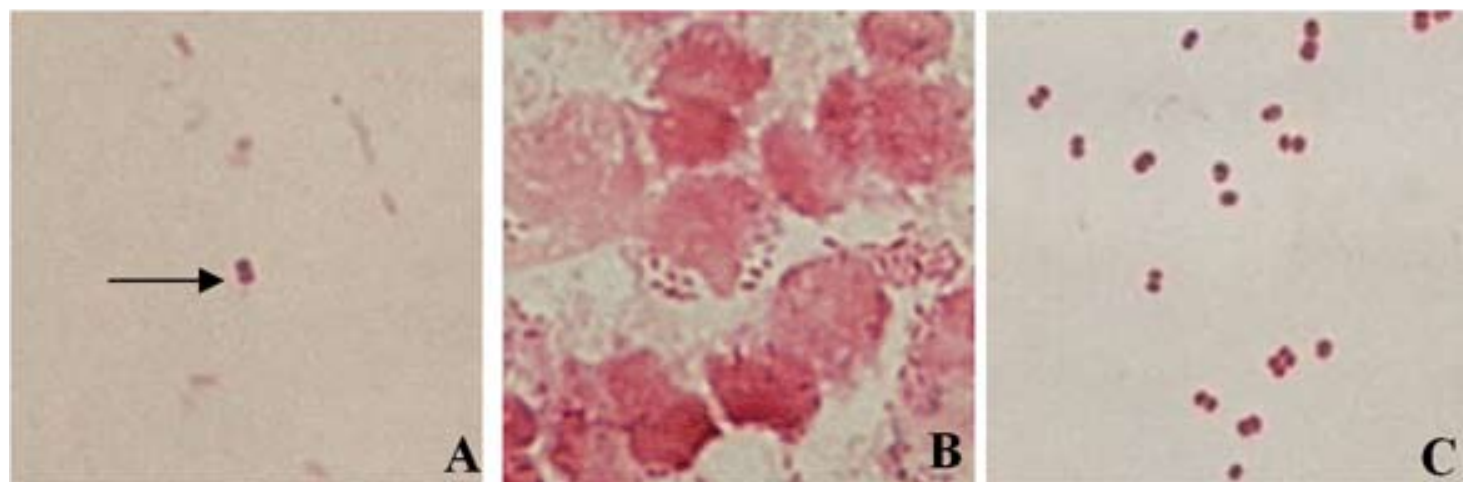

Figura 1. Comparación morfotintorial entre diplococos Gram negativos de frotis perianal y uretral de pacientes con cultivo negativo y aislados de N. gonorrhoeae procedente de muestra perianal. Coloración de Gram. 1000x. A. Frotis perianal mostrando bacteria con morfología semejante a diplococo Gram negativo (flecha). B. Frotis uretral mostrando diplococos intracelulares. C. Diplococos Gram negativos de cultivo de 24 horas de muestra uretral, identificándose N. gonorrhoeae. 


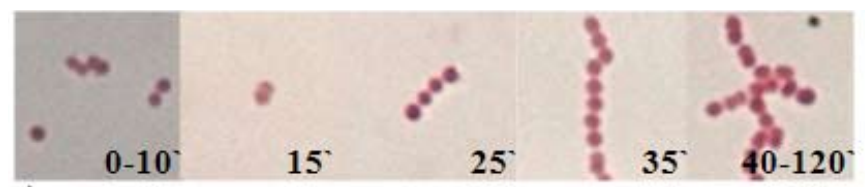

A

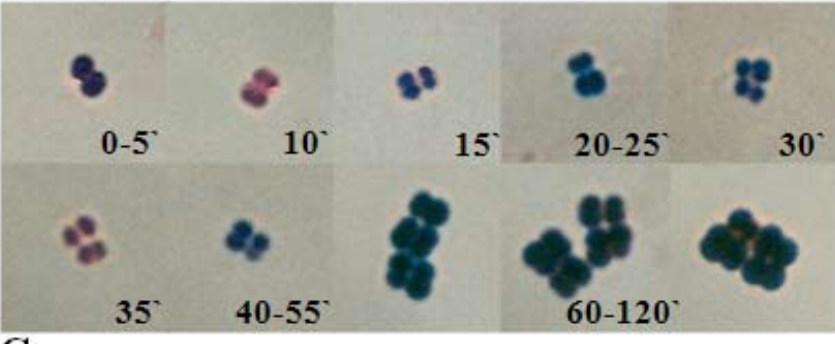

C

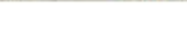

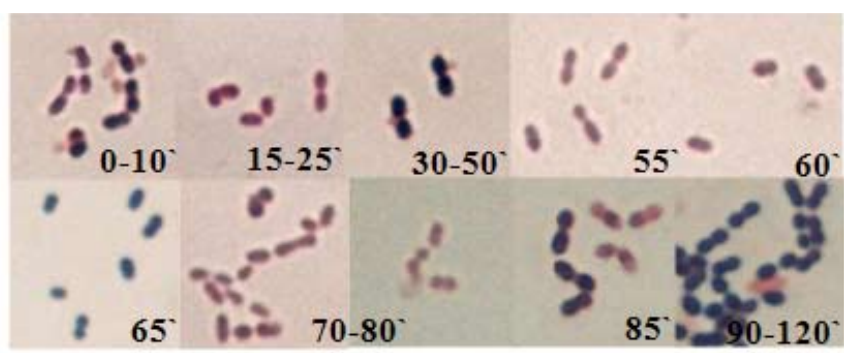

B

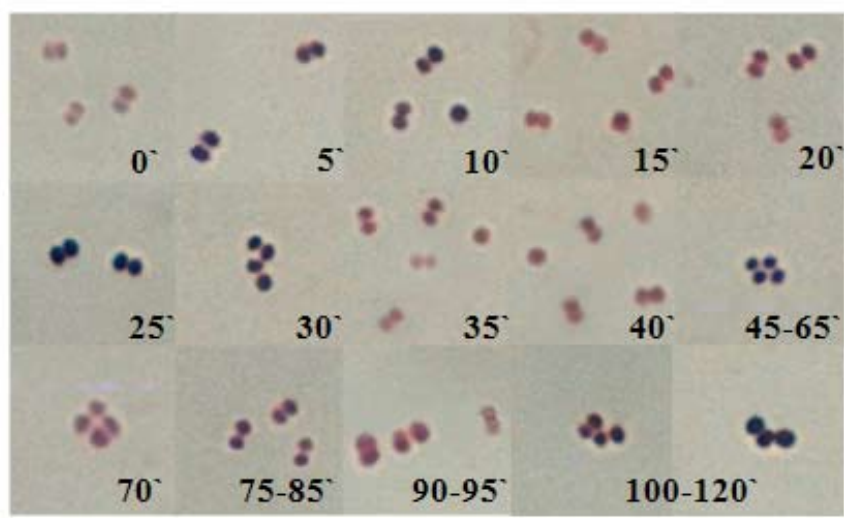

D

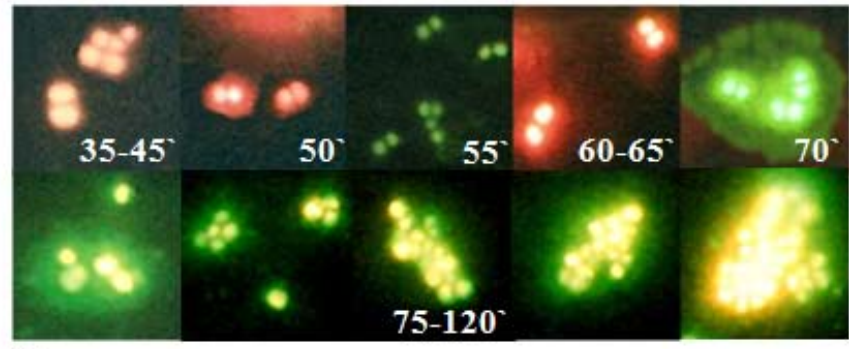

F
E

$40-120^{\circ}$ 20

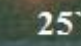

$30^{\circ}$

Figura 2. Cocos Gram positivos. 2A. Streptococcus $\beta$-hemolítico. 2B. E. faecalis. 2C. S. saprophyticus. 2D. S. epidermidis. Por fluorescencia 2 E S. saprophyticus y 2 F S. epidermidis.

la presencia de características morfotintoriales semejantes a diplococos Gram negativos o anaranjados fluorescentes, en los géneros bacterianos Staphylococcus, Streptococcus y Enterococcus, relacionándose estos aspectos morfológicos y tintoriales al ciclo celular bacteriano. Al respecto, la bibliografía ha reportado que en los frotis las especies del género Staphylococcus, Streptococcus y Enterococcus, se distinguen como cocos Gram positivos o Gram variables, semejando estas bacterias diplococos Gram negativos. No obstante, señala que las variaciones en la reacción de Gram se deban probablemente a la acción de células inflamatorias y de sus enzimas hidrolíticas sobre las células bacterianas (17-19).

Las diferentes tonalidades encontradas con la tinción de fluorescencia pueden explicarse sobre la base de la expresión genética durante el ciclo celular bacteriano, naturaleza química del colorante naranja de acridina y mecanismo de tinción, como fuera reportado por Flores y su equipo (15) y Albarado y Flores (3). La presencia de bacterias con tinción de fluorescencia que varia desde amarillo, pasando a verde y finalmente anaranjado, para nuevamente repetir tales tinciones, es un hallazgo que sugiere que la célula bacteriana se encuentra dentro de un evento cíclico.

Albarado y Flores, al evaluar la tinción de fluorescencia, con ensayos a diferentes intervalos de crecimiento en especies del género Pseudomonas, reportan que las variaciones de color e intensidad de fluorescencia en las bacterias representan distintas fases del ciclo celular bacteriano, explicando que es probable que el color verde mostrado en las células bacterianas, sea producto de la intercalación del naranja de acridina al $\mathrm{ADN}$, pudiendo 
corresponder a la fase $\mathrm{C}$ del ciclo celular bacteriano y, posiblemente, la intensidad de fluorescencia aumenta a medida que se incrementa el nivel de $\mathrm{ADN}$ en el proceso de duplicación (3).

Por otro lado, explican que las bacterias con tonalidad amarilla y anaranjada pueden corresponder a otras fases del ciclo celular bacteriano; las bacterias con coloración amarilla pueden encontrarse en la fase $\mathrm{D}$ dentro del ciclo celular bacteriano y posiblemente, esté relacionado con una fase inicial de síntesis de ARN, que al encontrarse en el citoplasma bacteriano en una menor cantidad, el colorante naranja de acridina es removido parcialmente por el decolorante alcohol-acetona, y que al incorporar la fluoresceína de sodio se forma el sistema rojo/verde, apareciendo la bacteria de color amarillo. Las bacterias anaranjadas fluorescentes, probablemente, correspondan a la fase innominada, pudiéndose encontrar en una activa síntesis de ARN, de manera que, el fluorocromo naranja de acridina no va poder ser removido por el alcohol-acetona y al aplicar el segundo colorante, fluoresceína de sodio, éste no va a producir el efecto diferencial, permaneciendo la bacteria anaranjada fluorescente.

Los resultados obtenidos permiten anotar que los cocos Gram positivos presentan durante el ciclo celular una fase de diplococos Gram negativos. Del mismo modo especies de Staphylococcus toman aspecto morfotintorial de diplococos anaranjados fluorescentes, sugiriéndose que las variaciones en la reactividad tintorial de la bacteria puede estar influenciada por constitución genética. De esta manera, con estos datos se estaría aportando información nueva relacionada con la fisiología bacteriana, proponiéndose continuar el estudio, incluyendo técnicas moleculares para confirmar dichos hallazgos.

\section{Agradecimientos}

A la Dra. Mireya Acuña, directora del aérea de ITSSIDA del ambulatorio "Dr. Arquímedes Fuentes Serrano" y a su personal de enfermería, quienes colaboraron en la atención al paciente y en la toma de muestras. Al Consejo de Investigación de la Universidad de Oriente por el aporte financiero del proyecto CI-2-040102-1284/06. NOVA

\section{Referencias}

1. Donachie W. What is the minimum number of dedicated functions required for a basic cell cycle? Curr Opin Genet Dev. 1992;2:792-798.

2. Donachie W. The cell cycle of Escherichia coli. Annu Rev Microbiol. 1993;47:199-230.

3. Albarado L, Flores E. Evaluación de la coloración diferencial de fluorescencia modificada en Pseudomonas spp. aisladas de suelo. Kasmera. 2008;36:17-27.

4. Angert E. Alternatives to binary fission in bacteria. Nat Rev Microbiol. 2005;3:214-224.

5. Weart R, Levin P. Growth rate-dependent regulation of medial FtsZ ring formation. J Bacteriol. 2003;185:2826-2834.

6. Michie KA, Löwe J. Dynamic filaments of the bacterial cytoskeleton. J. Annu Rev Biochem. 2006;75:467-492.

7. Margolin W. FtsZ and the division of prokaryotic cells and organelles. Nat Rev Mol Cell Biol. 2005;6:862-871

8. Midigan T, Martinko J, Parker J. Brock. Biología de los Microorganismos. Ed. 8a. Madrid: Prentice-Hall; 1998.

9. Dubytska L, Godfrey H, Cabello F. Borrelia burgdorferi ftsZ Plays a Role in Cell Division. Bacteriol. 2006:188:1969-1978.

10. Tobiason D, Seifert H. The obligate human pathogen, Neisseria gonorrhoeae, is polyploid. PLoS Biol. 2006;4:1069-1078.

11. Manavi K, Young H, Clutterbuck D. Sensitivity of microscopy for the rapid diagnosis of gonorrhoea in men and women and the role of gonorrhoea serovars. Int J STD AIDS. 2003;14:390-394.

12. CDC: Centers for Disease Control and Prevention. Screening tests to detect Chlamydia trachomatis and Neisseria gonorrhoeae infections. MMWR. 2002;51(RR15):1-27.

13. Unemo M, Savicheva A, Budilovskaya O, Sokolovsky E, Larsson M, Domeika M. Laboratory diagnosis of Neisseria gonorrhoeae in St Petersburg, Russia: inventory, performance characteristics and recommended optimisations. Sex Transm Infect. 2006;82:41-44.

14. Lai-King Ng, Martin I. The laboratory diagnosis of Neisseria gonorrhoeae. Can J Infect Dis Med Microbiol. 2005;16:15-25.

15. Flores E, Albarado L, Thomas D, Lobo A. Comparación de la tinción fluorescencia modificada y Gram, en muestras urogenitales y perianales de pacientes asistidos en el área de Infecciones de Transmisión Sexual del Ambulatorio Arquímedes Fuentes, Cumaná estado Sucre. Salus. 2008;12:29-35.

16. Flores E, Albarado L. Tinción diferencial de fluorescencia modificada en el diagnóstico de gonorrea. En: XIV Congreso Panamericano de Infectología. Sao Paulo: Office Editora e Publicidade Ltda; 2009. p. 67.

17. Koneman E, Allen S, Janda W, Schreckenberger P, Winn W. Diagnóstico microbiológico. Texto y atlas color. Ed. $5^{\text {a }}$. Buenos Aires: Editorial Médica Panamericana; 1999.

18. Salguero I. Replicación cromosómica en presencia de una nucleósido difosfato reductasa codificada por el alelo nrdA101 de Escherichia coli [tesis doctoral]. Badajoz: Servicio de publicaciones, Universidad de Extremadura; 2007.

19. Stainer R, Igraham J, Wheelis M, Painter P. Microbiología. Ed. 2a . Barcelona: Editorial Reverte S.A; 1991. 